\title{
Optimization of low-cost medium for very high gravity ethanol fermentations by Saccharomyces cerevisiae using statistical experimental designs
}

\author{
Francisco B. Pereira, Pedro M.R. Guimarães, José A. Teixeira, Lucília Domingues * \\ IBB - Institute for Biotechnology and Bioengineering, Centre of Biological Engineering, Universidade do Minho, Campus de Gualtar, 4710-057 Braga, Portugal
}

\section{A R T I C L E I N F O}

\section{Article history:}

Received 12 January 2010

Received in revised form 8 April 2010

Accepted 22 April 2010

Available online 2 June 2010

\section{Keywords:}

Very high gravity fermentation

Corn steep liquor

Ethanol

Response surface methodology

Saccharomyces cerevisiae

\begin{abstract}
A B S T R A C T
Statistical experimental designs were used to develop a medium based on corn steep liquor (CSL) and other low-cost nutrient sources for high-performance very high gravity (VHG) ethanol fermentations by Saccharomyces cerevisiae. The critical nutrients were initially selected according to a Plackett-Burman design and the optimized medium composition (44.3 g/L CSL; $2.3 \mathrm{~g} / \mathrm{L}$ urea; $3.8 \mathrm{~g} / \mathrm{L} \mathrm{MgSO}{ }_{4} \cdot 7 \mathrm{H}_{2} \mathrm{O} ; 0.03 \mathrm{~g} / \mathrm{L}$ $\mathrm{CuSO}_{4} \cdot 5 \mathrm{H}_{2} \mathrm{O}$ ) for maximum ethanol production by the laboratory strain CEN.PK 113-7D was obtained by response surface methodology, based on a three-level four-factor Box-Behnken design. The optimization process resulted in significantly enhanced final ethanol titre, productivity and yeast viability in batch VHG fermentations (up to $330 \mathrm{~g} / \mathrm{L}$ glucose) with CEN.PK113-7D and with industrial strain PE-2, which is used for bio-ethanol production in Brazil. Strain PE-2 was able to produce $18.6 \pm 0.5 \%$ (v/v) ethanol with a corresponding productivity of $2.4 \pm 0.1 \mathrm{~g} / \mathrm{L} / \mathrm{h}$. This study provides valuable insights into cost-effective nutritional supplementation of industrial fuel ethanol VHG fermentations.
\end{abstract}

(c) 2010 Elsevier Ltd. All rights reserved.

\section{Introduction}

Bio-ethanol is regarded as a promising alternative energy source, which is both renewable and environmentally friendly. During bio-ethanol production, the composition of media affects the physiological state and, consequently, the fermentation performance of the microorganism employed (Hahn-Hägerdal et al., 2005).

Ethanolic fermentations with very high sugar concentrations (>300 g/L) - very high gravity (VHG) fermentations - have many advantages from an industrial point of view, resulting in reduced costs because of lower energy consumption (Thomas et al., 1996). However, these fermentations are rarely fast and complete due to physiological changes in the microbial cells. The high sugar content in the fermentation medium causes an increase in the osmotic pressure, which has a damaging effect on yeast cells. Saccharomyces cerevisiae, the yeast commonly used for ethanolic fermentations, can ferment increased amount of sugars in the medium when all required nutrients are provided in adequate amounts (Bafrncová et al., 1999). Specific nutrients, such as nitrogen, trace elements or vitamins, are required to obtain rapid fermentation and high ethanol levels, desirable to minimize capital costs and distillation energy. On a laboratory scale, media are often supplemented with peptone and yeast extract. However, such addition is not feasible in industrial fermentation processes due

\footnotetext{
* Corresponding author. Tel.: +351253 604400; fax: +351253678986

E-mail address: luciliad@deb.uminho.pt (L. Domingues).
}

to the high costs associated. Thus, it is necessary to exploit inexpensive nutrient sources to supply all nutritional requirements for yeast growth and fermentation.

Corn steep liquor (CSL), a major by-product of corn starch processing, is a low-cost source of proteins, amino acids, minerals, vitamins and trace elements and can be used as a rich and effective nutritional supplement, in particular, as replacement for yeast extract and peptone in alcoholic fermentations (Amartey and Jeffries, 1994; Kadam and Newman, 1997; Lawford and Rousseau, 1997; Seo et al., 2009; Tang et al., 2006). Moreover, the effects of metal ions on yeast cell growth and fermentation are well documented. Magnesium, calcium and zinc have been reported to influence the rate of sugar conversion and are required as cofactors for several metabolic pathways (Palukurty et al., 2008; Xue et al., 2008; Zhao et al., 2009). Furthermore, the protective effects of magnesium and calcium against ethanol stress have been extensively studied (Birch and Walker, 2000; Nabais et al., 1988). Metal ion deficiencies often occur in fermentation media (Jones and Greenfield, 1984), and studies on optimization of metal ions combinations are thus of great practical importance to improve ethanol production.

Medium optimization by the classical method of changing one variable while fixing the others at a certain level is laborious and time-consuming, especially when the number of variables is large. An alternative and more efficient approach in microbial systems is the use of statistical methods. Response surface methodology (RSM) is a commonly used method to assess the optimal fermentation conditions and also an efficient statistical technique for opti- 
mization of multiple variables with minimum number of experiments. This method has been successfully applied to optimize alcoholic fermentation (Laluce et al., 2009; Palukurty et al., 2008; Ratnam et al., 2005; Yu et al., 2009). Plackett-Burman design allows testing of the largest number of factor effects with the least number of observations, and allows random error variability estimation and testing of the statistical significance of the parameters (Plackett and Burman, 1946). The Box-Behnken is a three-level factorial design, which allows estimating and interpreting interactions between various variables at a time during the optimization process. It is suitable for exploration of quadratic responses and constructs a second-order polynomial model with very few runs (Ferreira et al., 2007).

In this study, factorial design approaches were used to develop a low-cost medium based on CSL and other inexpensive nutrient sources for high-performance batch VHG ethanolic fermentations by $S$. cerevisiae. The supplements that significantly improved ethanol production by the laboratory strain CEN.PK 113-7D were selected according to Plackett-Burman designs and the concentrations of the key nutrient factors (CSL, urea, $\mathrm{MgSO}_{4}$ and $\mathrm{CuSO}_{4}$ ) were optimized using a Box-Behnken design. Furthermore, the optimized medium was compared with a reference medium containing CSL as the sole nutrient source, using the strain CEN.PK 113-7D as well as an industrial strain (PE-2).

\section{Methods}

\subsection{Yeasts}

The laboratory S. cerevisiae strain CEN.PK 113-7D (van Dijken et al., 2000) was used throughout the screening and optimization experimental designs. Final comparative fermentation tests were performed also with the industrial strain PE-2 (Basso et al., 2008). Stock cultures were maintained on YPD [yeast extract 1\% $(\mathrm{w} / \mathrm{v})$, bacto peptone $2 \%(\mathrm{w} / \mathrm{v})$ and glucose $2 \%(\mathrm{w} / \mathrm{v})]$ agar plates at $4{ }^{\circ} \mathrm{C}$.

\subsection{Media and fermentations}

For nutrient screening and optimization, fermentation tests were performed in basic medium (BM) consisting of 296-308 g/L glucose and $15 \mathrm{~g} / \mathrm{L}$ CSL, supplemented with nutrients according to the experimental designs (Tables 2 and 4). Glucose syrup and CSL were kindly provided by a starch manufacturer (COPAM, Portugal) and autoclaved separately $\left(121^{\circ} \mathrm{C}, 20 \mathrm{~min}\right)$. After autoclaving, the CSL was allowed to settle for $1-2$ days at $4{ }^{\circ} \mathrm{C}$ and then centrifuged ( $15 \mathrm{~min}$ at $13,100 \mathrm{~g}$ ) to remove the insolubles. The packed sediment corresponded to $15 \%(\mathrm{w} / \mathrm{w})$ of the whole CSL. The main composition of the centrifuged CSL (i.e. the supernatant after centrifugation) is shown in Table 1 . Batch 1 and batch 2 were

\section{Table 1}

Composition of the centrifuged CSL (values are average \pm range of duplicate analyses).

\begin{tabular}{lll}
\hline & Batch 1 & Batch 2 \\
\hline Density & $1.15 \pm 0.00$ & $1.13 \pm 0.02$ \\
Humidity (\%, w/w) & $65.4 \pm 0.1$ & $64.7 \pm 0.0$ \\
Ash $(\%, w / w)$ & $6.15 \pm 0.15$ & $5.97 \pm 0.46$ \\
Free reducing sugars $^{\mathrm{a}}(\%, \mathrm{w} / \mathrm{w})$ & $4.09 \pm 0.04$ & $3.82 \pm 0.14$ \\
Glucose $^{\mathrm{b}}(\%, \mathrm{w} / \mathrm{w})$ & $0.439 \pm 0.014$ & $0.408 \pm 0.006$ \\
Total Kjeldahl nitrogen $^{\mathrm{c}}(\%, \mathrm{w} / \mathrm{w})$ & $2.25 \pm 0.46$ & $2.26 \pm 0.04$ \\
Fat $^{\mathrm{d}}(\%, \mathrm{w} / \mathrm{w})$ & $3.19 \pm 0.80$ & $1.95 \pm 0.81$ \\
pH & 3.9 & 4.1 \\
\hline
\end{tabular}

a Determined by the DNS method (Miller, 1959), using glucose as standard.

b Determined by HPLC.

c Determined using the Tecator Kjeltec 1026 system.

d Determined using the Tecator Soxtec HT2 system. obtained from the same industrial plant approximately 3 months apart. The concentrated nutrient stock solutions were sterilized by filtration and added aseptically to the medium. A reference medium (RM) consisting of 290-330 g/L glucose and $100 \mathrm{~g} / \mathrm{L} \mathrm{CSL}$, and 2YP medium consisting of $290-330 \mathrm{~g} / \mathrm{L}$ glucose, $20 \mathrm{~g} / \mathrm{L}$ yeast extract and $40 \mathrm{~g} / \mathrm{L}$ peptone (i.e. the double of the yeast extract and peptone concentrations used in standard YP medium), were used for comparative studies. In all cases, the medium was aerated by stirring with a magnetic bar (length of $3 \mathrm{~cm}$ ) at $>850 \mathrm{rpm}$ during 20 min before inoculating the fermentation flasks, reaching $>95 \%$ of air saturation (approximately, 8 ppm of oxygen) (Munroe, 2006).

Yeast for inoculation was grown in $1 \mathrm{~L}$ Erlenmeyer flasks filled with $400 \mathrm{~mL}$ of medium containing $50 \mathrm{~g} / \mathrm{L}$ glucose, $20 \mathrm{~g} / \mathrm{L}$ peptone and $10 \mathrm{~g} / \mathrm{L}$ yeast extract. After incubation at $30^{\circ} \mathrm{C}$ and $150 \mathrm{rpm}$ for $24-26 \mathrm{~h}\left(\mathrm{OD}_{600}\right.$ of 7-7.5), the cell suspension was aseptically collected by centrifugation ( $10 \mathrm{~min}$ at $7500 \mathrm{~g}, 4^{\circ} \mathrm{C}$ ) and suspended in $0.9 \% \mathrm{NaCl}$ to a concentration of $200 \mathrm{mg}$ fresh yeast $/ \mathrm{mL}$, to minimize the transfer of nutrients from the seed culture to the fermentation medium. The yeast cells were inoculated at about $8 \mathrm{mg}$ fresh yeast/ $\mathrm{mL}$ into $40 \mathrm{~mL}$ of culture medium to start the fermentation.

Fermentations were done at $30^{\circ} \mathrm{C}$ and $150 \mathrm{rpm}$ in $100 \mathrm{~mL}$ Erlenmeyer flasks fitted with perforated rubber stoppers enclosing glycerol-filled air-locks to allow exhaustion of $\mathrm{CO}_{2}$ while avoiding entrance of air. The initial $\mathrm{pH}$ was adjusted to 5.5 with $\mathrm{NaOH}$ and the final pH was higher than 3.9 in all fermentations. The progress of fermentation was followed by mass loss. Samples for analyses were taken at the beginning and end of fermentation. The fermentation experiments were stopped when the weight of the flasks did not change anymore.

\subsection{Analytical procedures}

Yeast growth was monitored by measuring the optical density of the culture at $600 \mathrm{~nm}\left(\mathrm{OD}_{600}\right)$. Cell dry weight was determined by centrifugation $\left(10 \mathrm{~min}\right.$ at $7500 \mathrm{~g}, 4^{\circ} \mathrm{C}$ ) of $20 \mathrm{~mL}$ of the yeast culture in a pre-weighed dried tube, washing of the pellet with $20 \mathrm{~mL}$ of distilled water, drying overnight at $105^{\circ} \mathrm{C}$ and weighing. Glucose, ethanol and glycerol were analyzed by HPLC, using a Varian MetaCarb $87 \mathrm{H}$ column eluted at $60{ }^{\circ} \mathrm{C}$ with $0.005 \mathrm{M} \mathrm{H}_{2} \mathrm{SO}_{4}$ at a flow rate of $0.7 \mathrm{~mL} / \mathrm{min}$, and a refractive-index detector. Yeast cell number was determined with a Neubauer counting chamber and viability was determined by methylene blue staining (Mills, 1941).

\subsection{Experimental design}

A Plackett-Burmam design was performed to screen nine independent variables selected from the literature (Azenha et al., 2000; Kadam and Newman, 1997; Nabais et al., 1988; Palukurty et al., 2008; Wang et al., 2007; Xue et al., 2008; Zhao et al., 2009) as feasible supplements in alcoholic fermentations (g/L): CSL 25, urea $1.5,\left(\mathrm{NH}_{4}\right)_{2} \mathrm{SO}_{4} 5, \mathrm{MgSO}_{4} \cdot 7 \mathrm{H}_{2} \mathrm{O} 5, \mathrm{KH}_{2} \mathrm{PO}_{4} 2, \mathrm{ZnCl}_{2} 0.01, \mathrm{FeSO}_{4} \cdot 7 \mathrm{H}_{2} \mathrm{O}$ $0.0072, \mathrm{CuSO}_{4} \cdot 5 \mathrm{H}_{2} \mathrm{O} 0.075, \mathrm{CaCl}_{2} \cdot 2 \mathrm{H}_{2} \mathrm{O} 0.8$. For each variable, the presence and absence levels of supplements were tested (all trials were performed in duplicate), resulting in 13 independent experiments (Table 2). Significant positive variable effects were considered when the reported $p$-values were lower than 0.05 .

Furthermore, a Box-Behnken design was performed using the independent variables selected as significant in the screening design. Four replicates at the centre point level were also run to check if there was a non-linear relationship between the variables and the responses, leading to a total number of 28 trials (Table 4).

For predicting the optimal point, a second-order polynomial function was fitted to correlate the relationship between independent variables and response. $X_{1}, X_{2}, X_{3}$ and $X_{4}$ factors were correlated by the following equation: 
Table 2

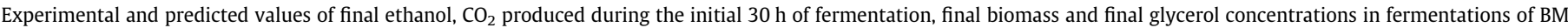
with $308 \mathrm{~g} / \mathrm{L}$ initial glucose supplemented according to the Plackett-Burman design.

\begin{tabular}{|c|c|c|c|c|c|c|c|c|c|c|c|c|c|c|c|c|c|}
\hline \multirow[t]{2}{*}{ Runs } & \multirow[t]{2}{*}{ CSL } & \multirow[t]{2}{*}{ Urea } & \multirow[t]{2}{*}{$\left(\mathrm{NH}_{4}\right)_{2} \mathrm{SO}_{4}$} & \multirow[t]{2}{*}{$\mathrm{MgSO}_{4}$} & \multirow{2}{*}{$\mathrm{KH}_{2} \mathrm{PO}_{4}$} & \multirow[t]{2}{*}{$\mathrm{ZnCl}_{2}$} & \multirow[t]{2}{*}{$\mathrm{FeSO}_{4}$} & \multirow[t]{2}{*}{$\mathrm{CuSO}_{4}$} & \multirow{2}{*}{$\mathrm{CaCl}_{2}$} & \multicolumn{2}{|c|}{ Ethanol (g/L) } & \multicolumn{2}{|c|}{$\mathrm{CO}_{2}$ at $30 \mathrm{~h}(\mathrm{~g} / \mathrm{L})$} & \multicolumn{2}{|c|}{ Biomass (g/L) } & \multicolumn{2}{|c|}{ Glycerol (g/L) } \\
\hline & & & & & & & & & & Exp. $^{a}$ & Mod. $^{b}$ & Exp. $^{a}$ & Mod. $^{\mathrm{b}}$ & Exp. $^{a}$ & Mod. $^{\mathrm{b}}$ & Exp. $^{a}$ & Mod. ${ }^{\mathrm{b}}$ \\
\hline $1-2$ & 0 & 0 & 0 & 5 & 0 & 0 & 0.0072 & 0 & 0.8 & $127.5 \pm 1.1$ & 127.4 & $45.4 \pm 0.9$ & 49.2 & $5.5 \pm 0.0$ & 5.7 & $8.7 \pm 0.2$ & 9.3 \\
\hline $3-4$ & 0 & 0 & 5 & 0 & 0 & 0.01 & 0 & 0.075 & 0.8 & $121.5 \pm 2.5$ & 119.1 & $47.6 \pm 0.5$ & 46.2 & $4.5 \pm 0.0$ & 4.4 & $8.5 \pm 0.0$ & 8.1 \\
\hline $5-6$ & 0 & 0 & 5 & 0 & 2 & 0.01 & 0.0072 & 0 & 0 & $105.0 \pm 1.0$ & 108.2 & $67.5 \pm 0.1$ & 70.3 & $5.3 \pm 0.3$ & 5.4 & $8.8 \pm 0.4$ & 9.6 \\
\hline $7-8$ & 0 & 1.5 & 0 & 0 & 2 & 0 & 0.0072 & 0.075 & 0.8 & $127.0 \pm 2.2$ & 128.7 & $46.3 \pm 0.1$ & 45.2 & $4.8 \pm 0.3$ & 4.6 & $8.7 \pm 0.2$ & 8.8 \\
\hline $9-10$ & 0 & 1.5 & 0 & 5 & 2 & 0.01 & 0 & 0 & 0 & $128.1 \pm 0.6$ & 125.7 & $72.6 \pm 0.2$ & 71.2 & $5.3 \pm 0.3$ & 5.2 & $10.5 \pm 1.6$ & 9.9 \\
\hline $11-12$ & 0 & 1.5 & 5 & 5 & 0 & 0 & 0 & 0.075 & 0 & $129.8 \pm 1.7$ & 132.2 & $43.5 \pm 0.5$ & 45.0 & $4.5 \pm 0.0$ & 4.6 & $10.0 \pm 0.0$ & 11.0 \\
\hline $13-14$ & 12.5 & 0.75 & 2.5 & 2.5 & 1 & 0.005 & 0.0036 & 0.0375 & 0.4 & $130.1 \pm 0.9$ & 125.9 & $70.1 \pm 0.1$ & 61.6 & $5.8 \pm 0.3$ & 5.6 & $12.0 \pm 0.0$ & 9.6 \\
\hline $15-16$ & 25 & 0 & 0 & 0 & 2 & 0 & 0 & 0.075 & 0 & $130.1 \pm 1.1$ & 129.2 & $62.3 \pm 0.0$ & 64.7 & $6.5 \pm 0.0$ & 6.7 & $7.8 \pm 0.0$ & 8.0 \\
\hline $17-18$ & 25 & 0 & 0 & 5 & 0 & 0.01 & 0.0072 & 0.075 & 0 & $128.6 \pm 0.3$ & 130.3 & $62.2 \pm 0.1$ & 61.1 & $6.5 \pm 0.0$ & 6.4 & $9.9 \pm 2.1$ & 10.0 \\
\hline $19-20$ & 25 & 0 & 5 & 5 & 2 & 0 & 0 & 0 & 0.8 & $128.0 \pm 1.0$ & 128.9 & $76.0 \pm 0.8$ & 73.5 & $6.5 \pm 0.0$ & 6.3 & $8.2 \pm 0.0$ & 7.9 \\
\hline $21-22$ & 25 & 1.5 & 0 & 0 & 0 & 0.01 & 0 & 0 & 0.8 & $131.2 \pm 0.5$ & 133.6 & $78.4 \pm 0.3$ & 79.8 & $6.0 \pm 0.0$ & 6.1 & $7.4 \pm 0.0$ & 7.8 \\
\hline $23-24$ & 25 & 1.5 & 5 & 0 & 0 & 0 & 0.0072 & 0 & 0 & $130.7 \pm 1.0$ & 129.1 & $77.8 \pm 0.3$ & 77.7 & $6.5 \pm 0.0$ & 6.4 & $10.1 \pm 2.0$ & 10.0 \\
\hline $25-26$ & 25 & 1.5 & 5 & 5 & 2 & 0.01 & 0.0072 & 0.075 & 0.8 & $131.4 \pm 2.4$ & 131.4 & $62.1 \pm 0.9$ & 65.9 & $4.8 \pm 0.3$ & 4.9 & $9.0 \pm 0.2$ & 9.6 \\
\hline
\end{tabular}

a Exp.: experimental value (average \pm range of duplicate independent biological experiments).

b Mod.: model-predicted value.

Table 3

Plackett-Burman design - effects of nutrient sources on the final ethanol titre.

\begin{tabular}{lllll}
\hline Term & Coefficient & Standard error & $t$-Value & $p$-Value \\
\hline $\mathrm{CSL}$ & 3.426 & 0.7006 & 4.890 & 0.0002 \\
$\mathrm{Urea}$ & 3.122 & 0.7006 & 4.460 & 0.0004 \\
$\mathrm{MgSO}_{4}$ & 2.326 & 0.7006 & 3.320 & 0.0043 \\
$\mathrm{ZnCl}_{2}$ & -2.269 & 0.7006 & -3.200 & 0.0051 \\
$\left(\mathrm{NH}_{4}\right)_{2} \mathrm{SO}_{4}$ & -2.165 & 0.7006 & -3.100 & 0.0007 \\
$\mathrm{KH}_{2} \mathrm{PO}_{4}$ & -1.626 & 0.7006 & -2.300 & 0.0338 \\
$\mathrm{CuSO}_{4}$ & 1.497 & 0.7006 & 2.140 & 0.0485 \\
$\mathrm{CaCl}_{2}$ & 1.192 & 0.7006 & 1.700 & 0.1083 \\
$\mathrm{FeSO}_{4}$ & -1.573 & 0.9376 & -1.700 & 0.1129 \\
\hline
\end{tabular}

$$
\begin{aligned}
Y= & b_{0}+b_{1} X_{1}+b_{2} X_{2}+b_{3} X_{3}+b_{4} X_{4}+b_{11} X_{1}^{2}+b_{22} X_{2}^{2}+b_{33} X_{3}^{2} \\
& +b_{44} X_{4}^{2}+b_{12} X_{1} X_{2}+b_{13} X_{1} X_{3}+b_{14} X_{1} X_{4}+b_{23} X_{2} X_{3} \\
& +b_{24} X_{2} X_{4}+b_{34} X_{3} X_{4}
\end{aligned}
$$

In Eq. (1), $Y$ is the predicted response corresponding to the ethanol titre at the end of the fermentation process. $X_{1}, X_{2}, X_{3}$ and $X_{4}$ are independent variables, $b_{0}$ is an offset term, $b_{1}, b_{2}, b_{3}$ and $b_{4}$ are linear effects and $b_{12}, b_{13}, b_{14}, b_{23}, b_{24}$ and $b_{34}$ are interaction terms.

A screening of vitamins (selected from the yeast mineral medium described by Verduyn et al. (1992)) was done in glucose medium containing the optimal concentration of nutrients $\left(X_{1}, X_{2}, X_{3}\right.$

Table 4

\begin{tabular}{|c|c|c|c|c|c|c|c|c|c|}
\hline \multirow[t]{2}{*}{ Run } & \multicolumn{4}{|c|}{ Factor $(\mathrm{g} / \mathrm{L})$} & \multicolumn{2}{|c|}{ Ethanol (g/L) } & \multirow{2}{*}{$\frac{\mathrm{CO}_{2} \text { at } 38 \mathrm{~h}(\mathrm{~g} / \mathrm{L})}{\text { Exp. }^{\mathrm{a}}}$} & \multirow{2}{*}{$\begin{array}{l}\text { Biomass }(\mathrm{g} / \mathrm{L})^{\text {Exp. }^{\mathrm{a}}}\end{array}$} & \multirow{2}{*}{$\begin{array}{l}\text { Glycerol }(\mathrm{g} / \mathrm{L}) \\
\text { Exp. }^{\mathrm{a}}\end{array}$} \\
\hline & $\operatorname{CSL}\left(X_{1}\right)$ & Urea $\left(X_{2}\right)$ & $\mathrm{MgSO}_{4} \cdot 7 \mathrm{H}_{2} \mathrm{O}\left(X_{3}\right)$ & $\mathrm{CuSO}_{4} \cdot 5 \mathrm{H}_{2} \mathrm{O}\left(X_{4}\right)$ & Exp. $^{a}$ & Mod. ${ }^{b}$ & & & \\
\hline 1 & 15 & 0.5 & 5 & 0.075 & 113.9 & 111.5 & 71.0 & 6.0 & 8.0 \\
\hline 2 & 15 & 1.5 & 2.5 & 0.075 & 115.7 & 121.0 & 71.7 & 6.5 & 7.3 \\
\hline 3 & 15 & 1.5 & 5 & 0.025 & 124.0 & 120.8 & 88.8 & 7.0 & 8.3 \\
\hline 4 & 15 & 1.5 & 5 & 0.125 & 110.6 & 112.8 & 71.2 & 6.0 & 9.1 \\
\hline 5 & 15 & 1.5 & 7.5 & 0.075 & 117.2 & 117.0 & 77.5 & 6.5 & 8.8 \\
\hline 6 & 15 & 2.5 & 5 & 0.075 & 129.2 & 128.1 & 86.7 & 7.5 & 9.1 \\
\hline 7 & 25 & 0.5 & 2.5 & 0.075 & 123.6 & 122.0 & 81.9 & 7.5 & 8.1 \\
\hline 8 & 25 & 0.5 & 5 & 0.025 & 118.2 & 122.2 & 88.4 & 7.0 & 7.7 \\
\hline 9 & 25 & 0.5 & 5 & 0.125 & 110.0 & 109.6 & 77.7 & 6.5 & 8.1 \\
\hline 10 & 25 & 0.5 & 7.5 & 0.075 & 113.2 & 114.7 & 80.7 & 6.5 & 7.7 \\
\hline 11 & 25 & 1.5 & 2.5 & 0.025 & 135.2 & 133.1 & 95.8 & 8.5 & 8.5 \\
\hline 12 & 25 & 1.5 & 2.5 & 0.125 & 118.9 & 116.2 & 86.7 & 6.5 & 8.7 \\
\hline 13 & 25 & 1.5 & 5 & 0.075 & 132.5 & 132.7 & 93.2 & 7.5 & 7.9 \\
\hline 14 & 25 & 1.5 & 5 & 0.075 & 132.4 & 132.7 & 93.5 & 8.5 & 8.6 \\
\hline 15 & 25 & 1.5 & 5 & 0.075 & 132.0 & 132.7 & 93.5 & 8.0 & 8.6 \\
\hline 16 & 25 & 1.5 & 5 & 0.075 & 133.9 & 132.7 & 92.3 & 8.0 & 8.6 \\
\hline 17 & 25 & 1.5 & 7.5 & 0.025 & 123.8 & 124.3 & 93.0 & 8.0 & 7.9 \\
\hline 18 & 25 & 1.5 & 7.5 & 0.125 & 112.5 & 112.4 & 85.3 & 6.5 & 8.7 \\
\hline 19 & 25 & 2.5 & 2.5 & 0.075 & 134.8 & 133.7 & 96.5 & 8.0 & 8.8 \\
\hline 20 & 25 & 2.5 & 5 & 0.025 & 134.4 & 134.1 & 96.2 & 7.5 & 8.8 \\
\hline 21 & 25 & 2.5 & 5 & 0.125 & 122.6 & 120.5 & 89.8 & 6.5 & 9.2 \\
\hline 22 & 25 & 2.5 & 7.5 & 0.075 & 126.5 & 128.4 & 94.2 & 7.5 & 8.7 \\
\hline 23 & 35 & 0.5 & 5 & 0.075 & 124.0 & 122.8 & 89.1 & 8.5 & 8.2 \\
\hline 24 & 35 & 1.5 & 2.5 & 0.075 & 128.6 & 130.7 & 95.8 & 8.5 & 8.3 \\
\hline 25 & 35 & 1.5 & 5 & 0.025 & 135.4 & 134.1 & 98.8 & 7.0 & 8.6 \\
\hline 26 & 35 & 1.5 & 5 & 0.125 & 110.2 & 113.8 & 92.3 & 7.0 & 7.9 \\
\hline 27 & 35 & 1.5 & 7.5 & 0.075 & 125.5 & 122.1 & 96.5 & 8.0 & 8.6 \\
\hline 28 & 35 & 2.5 & 5 & 0.075 & 131.4 & 131.6 & 99.0 & 7.5 & 8.9 \\
\hline
\end{tabular}

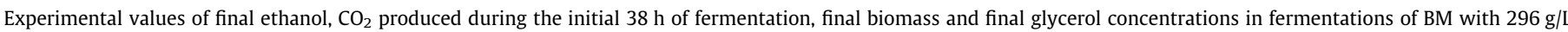
initial glucose supplemented according to the Box-Behnken design. The final ethanol concentrations predicted by the model are also shown.

a Exp.: experimental value.

b Mod.: model-predicted value. 
and $X_{4}$ ) predicted by the Box-Behnken model (designated optimized medium - OM) and supplemented, according to a Plackett-Burman design, with ( $\mathrm{mg} / \mathrm{L}$ ): biotin 0.1 , myo-inositol 100 , pantothenic acid 5, nicotinic acid 5, thiamine 5, pyridoxine 5 and p-aminobenzoic acid 1 (total number of 26 fermentation trials). Additionally, supplementation of OM with Tween $80(2.4 \mathrm{ml} / \mathrm{L})$, linoleic acid $(60 \mathrm{mg} / \mathrm{L})$ and ergosterol $(24 \mathrm{mg} / \mathrm{L})$ was also evaluated.

\subsection{Statistical analysis}

The JMPTM - The Statistical Discovery Software was used for generation and evaluation of the statistical experimental design. The optimized medium composition for ethanol production was obtained by solving the regression equation. The data from final comparative fermentations, between OM and RM were analyzed by SigmaStat 3.10 (Systat software).

\subsection{Determination of fermentation parameters}

Ethanol conversion yield was calculated as the ratio between the maximum ethanol concentration produced and the glucose consumed (difference between the initial and residual glucose concentrations) and expressed as a percentage (\%) of the theoretical conversion yield, i.e. the yield considering a production of $0.511 \mathrm{~g}$ of ethanol per $\mathrm{g}$ of glucose. Ethanol productivity was defined as the ratio between final ethanol concentration and total fermentation time (fermentation was considered to be complete when the mass loss stopped). The yeast viability was calculated as the ratio between viable (non-stained) and total cell counts.

\section{Results and discussion}

The development of a fermentation medium based on industrial substrates is economically desirable. CSL is a nutrient rich source and has been often used as a media supplement (Amartey and Jeffries, 1994; Jorgensen, 2009; Kadam and Newman, 1997; Lawford and Rousseau, 1997; Seo et al., 2009; Tang et al., 2006). To evaluate the feasibility of using CSL as the sole nutrient source to sustain high-performance VHG fermentation, fermentations of $300 \mathrm{~g} / \mathrm{L}$ glucose solutions supplemented with CSL in concentrations ranging from 5 to $150 \mathrm{~g} / \mathrm{L}$ were carried out. Increasing CSL concentration in the medium up to $110 \mathrm{~g} / \mathrm{L}$ led to enhanced ethanol production. The highest ethanol production ( $c a .125 \mathrm{~g} / \mathrm{L}$ ) was observed in fermentations with $75-110 \mathrm{~g} / \mathrm{L}$ CSL. A slight decrease in yield occurred when CSL concentration was raised to $150 \mathrm{~g} / \mathrm{L}$ (data not shown). Nevertheless, a fermentation medium with such high CSL concentration $(>75 \mathrm{~g} / \mathrm{L}$ ) could compromise the economical viability of industrial fermentation processes, because of the high costs associated with this supplementation. Thus, the partial replacement of CSL with other inexpensive nutrient sources was studied. As the starting condition for such medium development experiments, we have used a basic medium (BM) containing $15 \mathrm{~g} / \mathrm{L} \mathrm{CSL}$, therefore providing a minimum level of nutrients to support fermentation.

\subsection{Screening of nutrient supplements that enhance VHG fermentation}

Plackett-Burman design-based experiments were performed to select nutrients - metal ions, phosphate and nitrogen sources that could replace CSL and enhance fermentation parameters. The use of additional CSL was also introduced as one of the independent variables in the screening design, since its level in BM was low. The supplements were chosen on the basis of their cost and availability with a potential industrial utilization in mind. Ta- ble 2 shows the experimental data as well the values predicted by the models constructed using four distinct response variables: final ethanol titre, $\mathrm{CO}_{2}$ produced during the initial $30 \mathrm{~h}$ of fermentation, final biomass and final glycerol concentrations. Regression analysis showed that the models for ethanol titre $\left(R^{2}=0.85\right.$ and adjusted $\left.R^{2}=0.76\right), \mathrm{CO}_{2}$ at $30 \mathrm{~h}\left(R^{2}=0.93\right.$; adjusted $\left.R^{2}=0.89\right)$ and biomass $\left(R^{2}=0.93\right.$; adjusted $\left.R^{2}=0.89\right)$ are adequate, while the model for glycerol was not satisfactory. The significance of each coefficient was determined by student's $t$-test. The $p$-value was used as indicator of the statistical significance of the test. The results for the model using the final ethanol titre as the response are presented in Table 3, showing that CSL, urea and $\mathrm{MgSO}_{4}$, whose probability values are below 0.01 (significance level higher than 99\%), contributed significantly to enhancing the ethanol production in VHG fermentation. $\mathrm{CuSO}_{4}$ had also a significant positive effect on ethanol production ( $p<0.05$, i.e. significance level $>95 \%$ ) and the supplementation with $\mathrm{CaCl}_{2}$ showed a positive effect but its contribution was not significant ( $p$-value $>0.05$ ). The others supplements $\left(\mathrm{ZnCl}_{2}\right.$, $\left(\mathrm{NH}_{4}\right)_{2} \mathrm{SO}_{4}, \mathrm{KH}_{2} \mathrm{PO}_{4}$ and $\mathrm{FeSO}_{4}$ ) added to $\mathrm{BM}$ medium showed a negative effect on overall ethanol production (Table 3 ). The $\mathrm{CO}_{2}$ produced during the initial $30 \mathrm{~h}$ of fermentation was used as a parameter to assess the initial fermentation rate. Besides CSL and urea, $\mathrm{ZnCl}_{2}$ and $\mathrm{KH}_{2} \mathrm{PO}_{4}$ showed also a significant $(p<0.01)$ positive effect on the initial fermentation rate, with coefficients of 3.256 and 2.655, respectively (Table S1). Conversely, $\mathrm{CuSO}_{4}$ had a strong significant $(p<0.01)$ negative effect (Table S1). Similar qualitative results were obtained when considering the $\mathrm{CO}_{2}$ production at $48 \mathrm{~h}$ (Table S2). In terms of final biomass production, only CSL had a significant positive effect, while $\mathrm{CuSO}_{4}$, urea, $\mathrm{CaCl}_{2}$, $\left(\mathrm{NH}_{4}\right)_{2} \mathrm{SO}_{4}$ and $\mathrm{ZnCl}_{2}$ had significant $(p<0.01)$ negative impacts (Table S3).

Taken together, the results of the screening experiment show that addition of more CSL had the strongest contribution to enhancing the fermentation kinetics, improving the initial fermentation rate, the final ethanol titre and the final biomass concentration. Supplementation with urea had also a positive effect on the fermentation rate and on the ethanol titre. Amino nitrogen, the principal component of CSL and urea likely explain these results. The positive effect of increased free amino nitrogen concentration has frequently been reported during optimization processes of VHG fermentation medium (see e.g. Bafrncová et al., 1999; Dragone et al., 2003; Jones and Ingledew, 1994; Ratnam et al., 2005). Besides, CSL contains many other nutrients, including trace elements and vitamins (Akhtar et al., 1997) that likely have a positive impact on fermentation. Surprisingly, supplementation with $\left(\mathrm{NH}_{4}\right)_{2} \mathrm{SO}_{4}$ had a negative impact on the final ethanol titre (Table 3 ) and only a slight positive effect (not statistically significant) on the initial fermentation rate (Table S1). This observation indicates that the selection of the nitrogen source for VHG media affects the overall yeast fermentation performance. Addition of $\mathrm{MgSO}_{4}$ significantly increased the final ethanol titre (Table 3), which is in accordance with several reports describing a positive effect of magnesium ions on yeast ethanol tolerance and fermentation (Birch and Walker, 2000; Dombek and Ingram, 1986; Hu et al., 2003; Kadam and Newman, 1997; Wang et al., 2007). Magnesium seems to protect yeast cells during fermentation by a mechanism that results in decreased plasma membrane permeability under ethanol stress conditions (Birch and Walker, 2000; Hu et al., 2003). Supplementation with $\mathrm{CuSO}_{4}(0.3 \mathrm{mM})$ also had a significant positive effect on the final ethanol titre (Table 3), although it affected negatively the initial fermentation rate (Table S1) and the final biomass production (Table S3). Similarly, Azenha et al. (2000) observed that addition of copper (0.1-1 mM) to synthetic medium resulted in marked increases in ethanol production by $S$. cerevisiae, although the fermentations became slower. 


\subsection{Optimization of medium for VHG fermentations}

A three-level four-factor Box-Behnken experimental design was performed with BM supplemented with different combinations of the variables that were selected by the Plackett-Burman design as significant to enhance the final ethanol titre. Table 4 shows the experimental data and the values predicted by the model constructed using the final ethanol titre as the response variable. By applying multiple regression analysis on the experimental data, the following second-order polynomial equation giving the ethanol titre $(Y)$ as a function of CSL $\left(X_{1}\right)$, urea $\left(X_{2}\right), \mathrm{MgSO}_{4}\left(X_{3}\right)$ and $\mathrm{CuSO}_{4}$ $\left(X_{4}\right)$ concentrations was obtained:

$$
\begin{aligned}
Y= & 132.716+3.701 X_{1}+6.331 X_{2}-3.152 X_{3}-7.197 X_{4} \\
& -1.955 X_{1} X_{2}-1.156 X_{1} X_{3}+0.523 X_{2} X_{3}-2.956 X_{1} X_{4} \\
& -0.924 X_{2} X_{4}+1.249 X_{3} X_{4}-5.606 X_{1}^{2}-3.607 X_{2}^{2} \\
& -4.402 X_{3}^{2}-6.857 X_{4}^{2}
\end{aligned}
$$

For a good statistical model the $R^{2}$ value should be close to 1.0 where a value of 0.75 indicates the aptness of the model (Niladevi et al., 2009). The regression analysis of the data showed a good aptness of the proposed model with more than $93 \%$ variability in response being explained by the proposed model $\left(R^{2}\right.$ value of 0.9347 and adjusted $R^{2}$ value of 0.8644 ). This indicated that Eq. (2) was a suitable model to describe the response of the experiment to ethanol production.

The analysis of variance (ANOVA) of the quadratic regression model indicated that the model was highly significant, as the $F$ value for the model was $13.298(p=0.0001)$.

The results of Box-Behnken experiments showed both positive and negative dispersion of values (Table 5). The analysis of variance (ANOVA) of experimental data showed that medium supplementation with CSL, urea, $\mathrm{MgSO}_{4}$ and $\mathrm{CuSO}_{4}$ had a strongly linear effect on the response ( $p<0.01,99 \%$ significance). Increased concentrations of CSL and urea showed a positive correlation with ethanol production. Conversely, increased $\mathrm{MgSO}_{4}$ and $\mathrm{CuSO}_{4}$ concentrations in the medium had a negative effect on the maximum ethanol titre, possibly because CSL may already contain magnesium (Kadam and Newman, 1997) and copper ions and, consequently, low concentrations may be sufficient to complement CSL addition. Furthermore, there is a relatively narrow optimum concentration for copper and other heavy metals, which at high levels have toxic effects on yeast cells (Azenha et al., 2000).

The optimal concentrations of the four factors that maximize ethanol production were predicted using the optimization function (standard least squares numerical method) of the JMP ${ }^{\mathrm{TM}}-$ The Sta-

\begin{tabular}{|c|c|c|c|c|}
\hline Factor & Coefficient & Standard error & $t$-Value & $p$-Value \\
\hline Intercept & 132.72 & 1.5805 & 84.0 & 0.0000 \\
\hline CSL & 3.7011 & 0.91250 & 4.06 & 0.0014 \\
\hline Urea & 6.3313 & 0.91250 & 6.94 & 0.0000 \\
\hline $\mathrm{MgSO}_{4}$ & -3.1522 & 0.91250 & -3.45 & 0.0043 \\
\hline $\mathrm{CuSO}_{4}$ & -7.1970 & 0.91250 & -7.89 & 0.0000 \\
\hline $\mathrm{CSL} *$ urea & -1.9550 & 1.5805 & -1.24 & 0.2380 \\
\hline $\mathrm{CSL} * \mathrm{MgSO}_{4}$ & -1.1565 & 1.5805 & -0.730 & 0.4773 \\
\hline Urea $* \mathrm{MgSO}_{4}$ & 0.52250 & 1.5805 & 0.330 & 0.7462 \\
\hline $\mathrm{CSL} * \mathrm{CuSO}_{4}$ & -2.9557 & 1.5805 & -1.87 & 0.0841 \\
\hline Urea $* \mathrm{CuSO}_{4}$ & -0.92450 & 1.5805 & -0.580 & 0.5686 \\
\hline $\mathrm{MgSO}_{4} * \mathrm{CuSO}_{4}$ & 1.2490 & 1.5805 & 0.790 & 0.4436 \\
\hline $\mathrm{CSL} * \mathrm{CSL}$ & -5.6056 & 1.2905 & -4.34 & 0.0008 \\
\hline Urea $*$ urea & -3.6072 & 1.2905 & -2.80 & 0.0152 \\
\hline $\mathrm{MgSO}_{4} * \mathrm{MgSO}_{4}$ & -4.4022 & 1.2905 & -3.41 & 0.0046 \\
\hline $\mathrm{CuSO}_{4} * \mathrm{CuSO}_{4}$ & -6.8566 & 1.2905 & -5.31 & 0.0001 \\
\hline
\end{tabular}

\section{Table 5}

Box-Behnken design - standardized effects of nutrient supplementation on the final ethanol titre. tistical Discovery Software. CSL $44.3 \mathrm{~g} / \mathrm{L}$, urea $2.3 \mathrm{~g} / \mathrm{L}, \mathrm{MgSO}_{4} \cdot 7 \mathrm{H}_{2} \mathrm{O}$ $3.8 \mathrm{~g} / \mathrm{L}$ and $\mathrm{CuSO}_{4} \cdot 5 \mathrm{H}_{2} \mathrm{O} 0.03 \mathrm{~g} / \mathrm{L}$ were chosen as the optimal concentrations (optimized medium - OM), predicting a maximum ethanol production of $139 \mathrm{~g} / \mathrm{L}$. Eight independent fermentation runs at the above optimized conditions were carried out and an average response of $130 \pm 2 \mathrm{~g} / \mathrm{L}$ was achieved, which reached $94 \%$ of the predicted value by the software. The good agreement between the predicted and experimental results confirmed the validity of the model.

According to the screening experiment, besides CSL and urea, $\mathrm{ZnCl}_{2}$ and $\mathrm{KH}_{2} \mathrm{PO}_{4}$ also improved the initial fermentation rate significantly (Table S1), which is in agreement with previous reports on the positive effects of zinc and phosphorus in alcoholic fermentations (Xue et al., 2008; Yu et al., 2009; Zhao et al., 2009). However, supplementation of $\mathrm{OM}$ with $0.01 \mathrm{~g} / \mathrm{L} \mathrm{ZnCl}_{2}$ or $2 \mathrm{~g} / \mathrm{L} \mathrm{KH}_{2} \mathrm{PO}_{4}$ did not have any effect on the fermentation kinetics (Fig. S1), indicating that the demand for zinc and phosphorus was already fully covered by other components, most likely CSL.

\subsection{Screening of vitamin and lipid supplements}

Supplementation of OM with vitamins (biotin, myo-inositol, pantothenic acid, nicotinic acid, thiamine, pyridoxine and p-aminobenzoic acid) (Table S4) and lipids (Tween 80, linoleic acid and ergosterol) was tested, envisioning further improvements of the fermentation rate and/or ethanol production. The positive impacts of vitamins (Alfenore et al., 2002) and lipids, particularly linoleic acid (Moonjai et al., 2002), oleic acid (the main component in Tween 80) and ergosterol (Casey et al., 1984), on yeast fermentation have been reported in the literature. Analyses of variance (ANOVA) showed that supplementation of OM with vitamins did not contribute significantly ( $p$-value $>0.05$ ) to enhance the ethanol production in VHG fermentation (Table S5). The only vitamin showing a slightly positive effect on the final ethanol titre was biotin (coefficient of 0.378 ) but its contribution was not statistically significant ( $p=0.055$ ) (Table S5). Similarly, no improvements of final ethanol production and fermentation kinetics were observed when OM was supplemented with unsaturated fatty acids (linoleic acid or Tween 80) or ergosterol (Fig. S2). These results indicate that the yeast's requirement for vitamins and lipids was also fulfilled by CSL.

\subsection{VHG fermentations with the optimized medium using laboratory and industrial strains}

The significance of this medium optimization process was studied in VHG fermentations with the laboratory strain CEN.PK 1137D and with the industrial strain PE-2, which has been isolated from bio-ethanol production facilities in Brazil and is currently one of the most widely used strains in Brazilian distilleries (Argueso et al., 2009; Basso et al., 2008). Hence, several fermentations of glucose $(290-330 \mathrm{~g} / \mathrm{L})$ to ethanol were performed to compare the optimized medium (OM) with a reference medium (RM) that contained $100 \mathrm{~g} / \mathrm{L} \mathrm{CSL}$ as the sole nutrient source (Table 6). Fermentation progression is illustrated by the $\mathrm{CO}_{2}$ production (mass loss) profiles shown in Fig. 1. Under the oxygen-limiting conditions used in this study, the kinetics of ethanol production closely followed the pattern of $\mathrm{CO}_{2}$ evolution. Under VHG conditions, the final ethanol titres in RM were higher (relative increase $c a$. 6\%) than those in standard double-strength YP medium (2YP), although the initial fermentation rates were similar in these media (Fig. 1).

With strain CEN.PK 113-7D, the maximum ethanol concentration in fermentations with approximately $290-300 \mathrm{~g} / \mathrm{L}$ initial glucose was significantly higher $(n=8, p$-value $<0.01)$ in OM $(130 \mathrm{~g} /$ $\mathrm{L})$ than in $\mathrm{RM}(120 \mathrm{~g} / \mathrm{L})$, corresponding to a relative increase of $8 \%$. This clear improvement in ethanol production was not evident 
Table 6

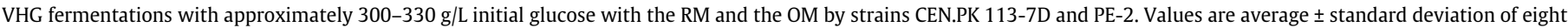

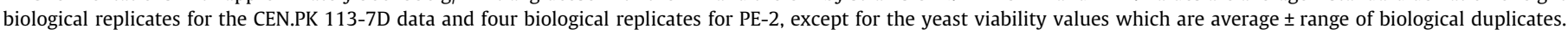

\begin{tabular}{|c|c|c|c|c|}
\hline \multirow{2}{*}{$\begin{array}{l}\text { Strain } \\
\text { Medium }\end{array}$} & \multicolumn{2}{|c|}{ CEN.PK 113-7D } & \multicolumn{2}{|l|}{ PE-2 } \\
\hline & RM & $\mathrm{OM}$ & RM & $\mathrm{OM}$ \\
\hline Initial glucose $(\mathrm{g} / \mathrm{L})$ & $290 \pm 4$ & $297 \pm 6$ & $322 \pm 4$ & $316 \pm 14$ \\
\hline Maximum ethanol concentration (g/L) & $120 \pm 3$ & $130 \pm 2$ & $130 \pm 0$ & $147 \pm 4$ \\
\hline Maximum ethanol titre $(\%, v / v)$ & $15.2 \pm 0.4^{\mathrm{a}}$ & $16.5 \pm 0.3^{b}$ & $16.5 \pm 0.0^{\mathrm{c}}$ & $18.6 \pm 0.5^{\mathrm{d}}$ \\
\hline Residual glucose $(\mathrm{g} / \mathrm{L})$ & $17.6 \pm 5.0$ & $4.3 \pm 2.8$ & $13.5 \pm 0.1$ & $0.6 \pm 1.0$ \\
\hline Final glycerol $(\mathrm{g} / \mathrm{L})$ & $10.3 \pm 0.5$ & $9.9 \pm 0.5$ & $10.8 \pm 0.1$ & $13.3 \pm 0.9$ \\
\hline Final biomass $(\mathrm{g} / \mathrm{L})$ & $7.0 \pm 0.8$ & $7.5 \pm 0.8$ & $9.8 \pm 0.8$ & $9.6 \pm 0.6$ \\
\hline Ethanol yield (\% of the theoretical value) & $86 \pm 2$ & $87 \pm 3$ & $81 \pm 0$ & $93 \pm 5$ \\
\hline Final ethanol productivity $(\mathrm{g} / \mathrm{L} / \mathrm{h})$ & $1.74 \pm 0.15$ & $1.87 \pm 0.21$ & $1.67 \pm 0.00$ & $2.41 \pm 0.10$ \\
\hline Yeast viability (\%) & $64 \pm 7^{e}$ & $85 \pm 3^{f}$ & $43 \pm 4^{g}$ & $89 \pm 2^{\mathrm{h}}$ \\
\hline
\end{tabular}

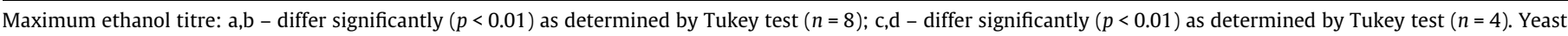
viability: e,f; g,h - differ significantly $(p<0.05)$ as determined by Tukey test $(n=2)$.
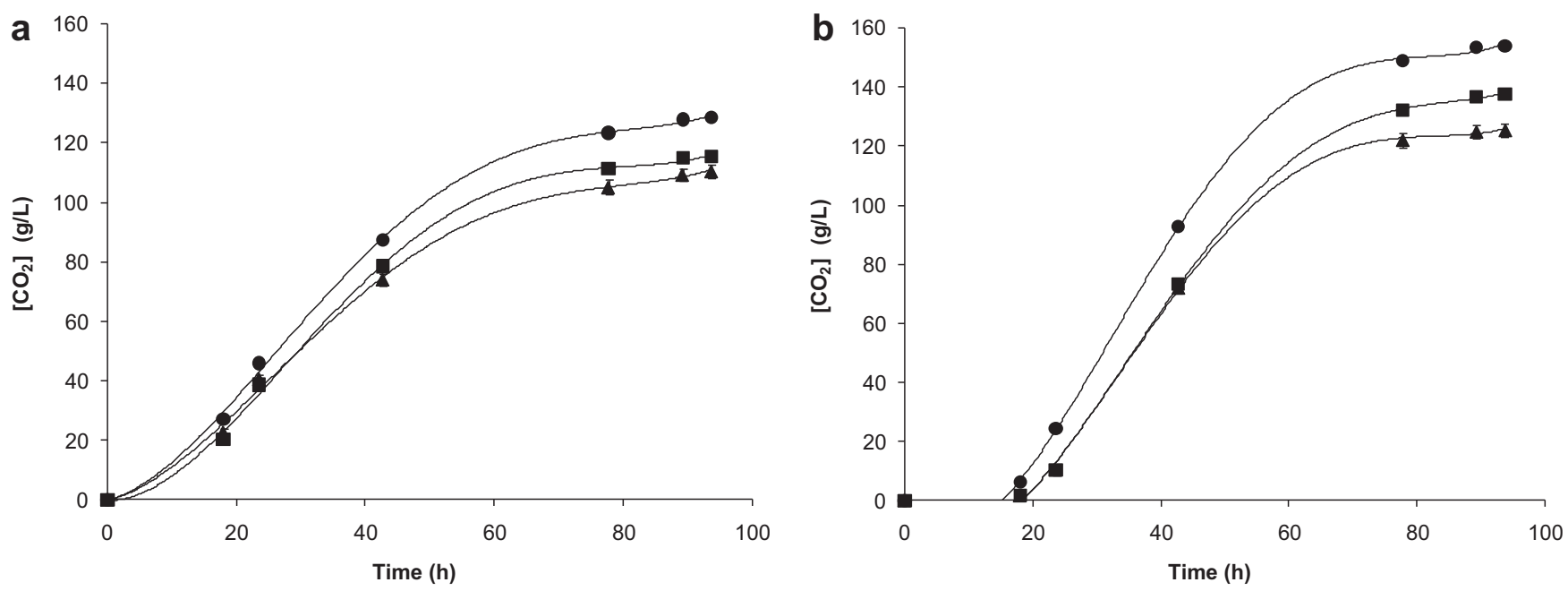

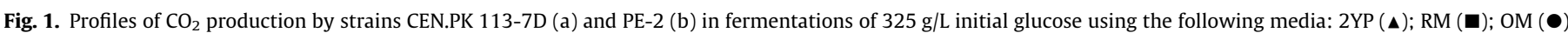

in the final biomass concentration obtained in RM and OM (Table 6). Supplementation with optimal nutrients concentrations resulted also in higher fermentation rate (Fig. 1a) and a higher overall ethanol productivity (relative increase of 7\%) (Table 6). With $c a .300 \mathrm{~g} / \mathrm{L}$ initial glucose, only $4.3 \mathrm{~g} / \mathrm{L}$ of residual glucose remained unconsumed. However, when the initial glucose concentration was raised close to $330 \mathrm{~g} / \mathrm{L}$, the fermentation stopped when the sugar residual was still $45 \mathrm{~g} / \mathrm{L}$ (data not shown), possibly due to ethanol inhibition or a synergistic effect between high concentrations of ethanol and glucose in the late stages of fermentation (see Casey and Ingledew, 1986 and references therein). Furthermore, this increase in the initial glucose concentration resulted in a considerable decrease in the fermentation rate (slower fermentation) and, consequently, in overall ethanol productivity, probably due to the increased osmotic pressure (higher content of sugar) at the beginning of the fermentation process (Pratt et al., 2003).

With strain PE-2, the maximum ethanol concentration in fermentations of $300-330 \mathrm{~g} / \mathrm{L}$ initial glucose was also significantly higher $(n=4, p$-value $<0.01)$ in OM $(147 \mathrm{~g} / \mathrm{L})$ compared to RM $(130 \mathrm{~g} / \mathrm{L})$, corresponding to a relative increase of $13 \%$ (Table 6$)$. The fermentation rate was also enhanced by optimal supplementation (Fig. 1b), contributing to a relative increase of $44 \%$ in the overall ethanol productivity (Table 6).

The influence of the medium optimization process on yeast viability was also investigated. Near the end of fermentations, i.e. at the point in which an ethanol titre of $15.0 \pm 0.4 \%(\mathrm{v} / \mathrm{v})$ was reached, the viability of strain CEN.PK 113-7D has improved from 64\% in RM to $85 \%$ in OM (Table 6 ). Similarly, when the ethanol titre reached $16.8 \pm 0.3 \%(\mathrm{v} / \mathrm{v})$, the viability of PE-2 cells improved from $43 \%$ in RM to $89 \%$ in OM (Table 6). For both strains, the increases in cell viability were statistically significant at the $95 \%$ level ( $n=2, p$-value $<0.05$ ). The higher viability possibly resulted from a higher ethanol tolerance reflecting the fact that medium supplementation with metal ions, principally magnesium, exhibited protective effect against ethanol toxicity (Xue et al., 2008).

Strain CEN.PK 113-7D was unable to ferment more than $300 \mathrm{~g} / \mathrm{L}$ glucose, while the results indicate that the industrial strain PE-2 was less sensitive to osmotic pressure and ethanol stress, being able to consume $330 \mathrm{~g} / \mathrm{L}$ glucose and produce a higher ethanol titre (Table 6).

Rapid fermentations and high final ethanol titres are highly desired by the ethanol industry. Ethanol concentrations as high as the maximum of $18.6 \pm 0.5 \%(\mathrm{v} / \mathrm{v})$ obtained in this work with the strain PE-2 have only rarely been reported in the literature. Moreover, the corresponding productivity of $2.4 \pm 0.1 \mathrm{~g} / \mathrm{L} / \mathrm{h}$ and ethanol yield of $93 \pm 5 \%$ (Table 6 ) are very interesting for batch VHG fermentation. To our knowledge, the highest ethanol titres (20.6-23.8\%, v/v) were obtained in fermentations of VHG wheat mashes at temperatures not higher than $27^{\circ} \mathrm{C}$ (Jones and Ingledew, 1994; Thomas et al., 1993; Thomas and Ingledew, 1992). However, at $30^{\circ} \mathrm{C}$ the ethanol titre decreased to about $18 \%$ with a productivity of $c a .2 .6 \mathrm{~g} / \mathrm{L} / \mathrm{h}$, using supplementation with urea $(0.96 \mathrm{~g} / \mathrm{L})$ (Jones and Ingledew, 1994). Alfenore et al. (2002) reported a final ethanol titre of $19 \%$ 
$(\mathrm{v} / \mathrm{v})$ and a productivity of $3.3 \mathrm{~g} / \mathrm{L} / \mathrm{h}$, but these authors have used an aerated $(0.2 \mathrm{vvm})$ glucose fed-batch process with an exponential vitamin feeding strategy. Most recently, Seo et al. (2009) reported an ethanol concentration of $160 \mathrm{~g} / \mathrm{L}$ (i.e. $20.3 \%$, v/v) with an overall productivity of $c a .2 .0 \mathrm{~g} / \mathrm{L} / \mathrm{h}$, obtained in a glucose fedbatch process with $0.13 \mathrm{vvm}$ aeration.

Although our optimization process was conducted with a laboratory strain, similar enhancement of VHG fermentation was observed with an industrial strain, suggesting that $\mathrm{OM}$ can be useful to test and compare the fermentative capacity of different strains. In fact, there is a lack of suitable media to test yeast strain performance under VHG conditions, since standard laboratory media that have been designed for cultivation with much lower sugar concentrations are nutrient-limited for VHG fermentations (Fig. 1). The OM described here is based on low-cost substrates and is adequate to test the limits of yeasts in terms of sugar consumption and ethanol production.

Our results show that the screening and optimization methodologies described here were effective not only in lowering the amount of CSL needed ( $44.3 \mathrm{~g} / \mathrm{L}$ CSL in OM) to sustain fast and complete VHG fermentation, but also in significantly improving the kinetics of VHG fermentations, permitting to reach higher final ethanol titres and productivities.

\section{Conclusions}

A response surface methodology was successfully employed to optimize a VHG fermentation medium based in CSL and other low-cost nutrients for the efficient production of ethanol from glucose by $S$. cerevisiae. Using the optimized medium composition ( $\mathrm{g} /$ L: CSL 44.3, urea 2.3, $\mathrm{MgSO}_{4} \cdot 7 \mathrm{H}_{2} \mathrm{O} 3.8$ and $\mathrm{CuSO}_{4} \cdot 5 \mathrm{H}_{2} \mathrm{O} 0.03$ ), industrial strain PE-2 was able to ferment up to $330 \mathrm{~g} / \mathrm{L}$ glucose and produce $18.6 \%(\mathrm{v} / \mathrm{v})$ ethanol, with a batch productivity of $2.4 \mathrm{~g} / \mathrm{L} / \mathrm{h}$ and an ethanol yield of $93 \%$. The screening and optimization methodologies described here represent valuable tools for the development of cost-effective industrial fermentation media.

\section{Acknowledgements}

The authors thank Marisa Cunha for performing the preliminary fermentations with varying CSL concentrations, COPAM - Companhia Portuguesa de Amidos, S.A. (Portugal) for kindly providing glucose syrup and CSL, and Rosane Schwan (University of Lavras, Brazil) for kindly providing the yeast strain PE-2. The financial support of Fundação para a Ciência e a Tecnologia (FCT), Portugal, is acknowledged: Project ProBioethanol PTDC/BIO/66151/2006, Grant SFRH/BD/64776/2009 to F.B. Pereira and Grant SFRH/BPD/ $44328 / 2008$ to P.M.R. Guimarães.

\section{Appendix A. Supplementary data}

Supplementary data associated with this article can be found, in the online version, at doi:10.1016/j.biortech.2010.04.082.

\section{References}

Akhtar, M., Lentz, M.J., Blanchette, R.A., Kirk, T.K., 1997. Corn steep liquor lowers the amount of inoculum for biopulping. Tappi J. 80, 161-164.

Alfenore, S., Molina-Jouve, C., Guillouet, S.E., Uribelarrea, J.L., Goma, G., Benbadis, L. 2002. Improving ethanol production and viability of Saccharomyces cerevisiae by a vitamin feeding strategy during fed-batch process. Appl. Microbiol. Biotechnol. 60, 67-72.

Amartey, S., Jeffries, T.W., 1994. Comparison of corn steep liquor with other nutrients in the fermentation of D-xylose by Pichia stipitis CBS 6054. Biotechnol. Lett. 16, 211-214

Argueso, J.L., Carazzolle, M.F., Mieczkowski, P.A., Duarte, F.M., Netto, O.V.C., Missawa, S.K., Galzerani, F., Costa, G.G.L., Vidal, R.O., Noronha, M.F., Dominska, M., Andrietta, M.G.S., Andrietta, S.R., Cunha, A.F., Gomes, L.H., Tavares, F.C.A.,
Alcarde, Dietrich, F.S., McCusker, J.H., Petes, T.D., Pereira, G.A.G., 2009. Genome structure of a Saccharomyces cerevisiae strain widely used in bioethanol production. Genome Res. 19, 2258-2270.

Azenha, M., Vasconcelos, M.T., Moradas-Ferreira, P., 2000. The influence of $\mathrm{Cu}$ concentration on ethanolic fermentation by Saccharomyces cerevisiae. J. Biosci. Bioeng. 90, 163-167.

Bafrncová, P., Smogrovicová, D., Sláviková, I., Pátková, J., Dömény, Z., 1999 Improvement of very high gravity ethanol fermentation by media supplementation using Saccharomyces cerevisiae. Biotechnol. Lett. 21, 337-341.

Basso, L.C., Amorim, H.V., Oliveira, A.J., Lopes, M.L., 2008. Yeast selection for fuel ethanol production in Brazil. FEMS Yeast Res. 8, 1155-1163.

Birch, R.M., Walker, G.M., 2000. Influence of magnesium ions on heat shock and ethanol stress responses of Saccharomyces cerevisiae. Enzyme Microb. Technol. 26, 678-687

Casey, G.P., Ingledew, W.M., 1986. Ethanol tolerance in yeasts. CRC Crit. Rev. Microbiol. 13, 219-280.

Casey, G.P., Magnus, C.A., Ingledew, W.M., 1984. High-gravity brewing: effects of nutrition on yeast composition, fermentative ability, and alcohol production. Appl. Environ. Microbiol. 48, 639-646.

Dombek, K.M., Ingram, L.O., 1986. Magnesium limitation and its role in apparent toxicity of ethanol during yeast fermentation. Appl. Environ. Microbiol. 52, 975981.

Dragone, G., Silva, D.P., Silva, J.B.A., Lima, U.A., 2003. Improvement of the ethanol productivity in a high gravity brewing at pilot plant scale. Biotechnol. Lett. 25, 1171-1174.

Ferreira, S.L.C., Bruns, R.E., Ferreira, H.S., Matos, G.D., David, J.M., Brandao, G.C., da Silva, E.G.P., Portugal, L.A., Reis, P.S., Souza, A.S., dos Santos, W.N.L., 2007. BoxBehnken design: an alternative for the optimization of analytical methods. Anal Chim. Acta 597, 179-186.

Hahn-Hägerdal, B., Karhumaa, K., Larsson, C.U., Gorwa-Grauslund, M., Gorgens, J., van Zyl, W.H., 2005. Role of cultivation media in the development of yeast strains for large scale industrial use. Microb. Cell Fact. 4, 31.

Hu, C.K., Bai, F.W., An, L.J., 2003. Enhancing ethanol tolerance of a self-flocculating fusant of Schizosaccharomyces pombe and Saccharomyces cerevisiae by $\mathrm{Mg}^{2+}$ via reduction in plasma membrane permeability. Biotechnol. Lett. 25, 1191-1194.

Jones, R.P., Greenfield, P.F., 1984. A review of yeast ionic nutrition. Part I. Growth and fermentation requirements. Process Biochem. 19, 48-62.

Jones, A.M., Ingledew, W.M., 1994. Fuel alcohol production: optimization of temperature for efficient very-high-gravity fermentation. Appl. Environ. Microbiol. 60, 1048-1051.

Jorgensen, H., 2009. Effect of nutrients on fermentation of pretreated wheat straw at very high dry matter content by Saccharomyces cerevisiae. Appl. Biochem. Biotechnol. 153, 44-57.

Kadam, K.L., Newman, M.M., 1997. Development of a low-cost fermentation medium for ethanol production from biomass. Appl. Microbiol. Biotechnol. 47, 625-629.

Laluce, C., Tognolli, J.O., Oliveira, K.F., Souza, C.S., Morais, M.R., 2009. Optimization of temperature, sugar concentration, and inoculum size to maximize ethanol production without significant decrease in yeast cell viability. Appl. Microbiol. Biotechnol. 83, 627-637.

Lawford, H.G., Rousseau, J.D., 1997. Corn steep liquor as a cost-effective nutrition adjunct in high-performance Zymomonas ethanol fermentations. Appl. Biochem. Biotechnol. 63-65, 287-304.

Miller, G.L., 1959. Use of dinitrosalicylic acid reagent for determination of reducing sugar. Anal. Chem. 31, 426-428.

Mills, D.R., 1941. Differential staining of living and dead yeast cells. Food Res. 6 361-371.

Moonjai, N., Verstrepen, K.J., Delvaux, F.R., Derdelinckx, G., Verachtert, H., 2002. The effects of linoleic acid supplementation of cropped yeast on its subsequent fermentation performance and acetate ester synthesis. J. Inst. Brew. 108, 227 235.

Munroe, J.H., 2006. Fermentation. In: Priest, F.G., Stewart, G.G. (Eds.), Handbook of Brewing. CRC Press, Boca Raton, FL, pp. 487-524.

Nabais, R.C., Sá-Correia, I., Viegas, C.A., Novais, J.M., 1988. Influence of calcium ion on ethanol tolerance of Saccharomyces bayanus and alcoholic fermentation by yeasts. Appl. Environ. Microbiol. 54, 2439-2446.

Niladevi, K.N., Sukumaran, R.K., Jacob, N., Anisha, G.S., Prema, P., 2009. Optimization of laccase production from a novel strain-Streptomyces psammoticus using response surface methodology. Microbiol. Res. 164, 105-113.

Palukurty, M.A., Telgana, N.K., Bora, H.S.R., Mulampaka, S.N., 2008. Screening and optimization of metal ions to enhance ethanol production using statistical experimental designs. Afr. J. Microbiol. Res. 2, 87-94.

Plackett, R.L., Burman, J.P., 1946. The design of optimum multifactorial experiments Biometrika 33, 305-325.

Pratt, P.L., Bryce, J.H., Stewart, G.G., 2003. The effects of osmotic pressure and ethanol on yeast viability and morphology. J. Inst. Brew. 109, 218-228.

Ratnam, B.V.V., Rao, S.S., Rao, M.D., Rao, M.N., Ayyanna, C., 2005. Optimization of medium constituents and fermentation conditions for the production of ethano from palmyra jaggery using response surface methodology. World J. Microbiol. Biotechnol. 21, 399-404.

Seo, H.B., Kim, S.S., Lee, H.Y., Jung, K.H., 2009. High-level production of ethanol during fed-batch ethanol fermentation with a controlled aeration rate and nonsterile glucose powder feeding of Saccharomyces cerevisiae. Biotechnol. Bioprocess Eng. 14, 591-598.

Tang, Y., An, M., Liu, K., Nagai, S., Shigematsu, T., Morimura, S., Kida, K., 2006. Ethanol production from acid hydrolysate of wood biomass using the 
flocculating yeast Saccharomyces cerevisiae strain KF-7. Process Biochem. 41 909-914.

Thomas, K.C., Ingledew, W.M., 1992. Production of $21 \%(\mathrm{v} / \mathrm{v})$ ethanol by fermentation of very high gravity (VHG) wheat mashes. J. Ind. Microbiol. 10, 61-68.

Thomas, K.C., Hynes, S.H., Jones, A.M., Ingledew, W.M., 1993. Production of fuel alcohol from wheat by VHG technology - effect of sugar concentration and fermentation temperature. Appl. Biochem. Biotechnol. 43, 211-226.

Thomas, K.C., Hynes, S.H., Ingledew, W.M., 1996. Practical and theoretical considerations in the production of high concentrations of alcohol by fermentation. Process Biochem. 31, 321-331.

van Dijken, J.P., Bauer, J., Brambilla, L., Duboc, P., François, J.M., Gancedo, C. Giuseppin, M.L.F., Heijnen, J.J., Hoare, M., Lange, H.C., Madden, E.A. Niederberger, P., Nielsen, J., Parrou, J.L., Petit, T., Porro, D., Reuss, M., van Riel, N., Rizzi, M., Steensma, H.Y., Verrips, C.T., Vindelov, J., Pronk, J.T., 2000. An interlaboratory comparison of physiological and genetic properties of four Saccharomyces cerevisiae strains. Enzyme Microb. Technol. 26, 706714.

Verduyn, C., Postma, E., Scheffers, W.A., van Dijken, J.P., 1992. Effect of benzoic acid on metabolic fluxes in yeasts: a continuous culture study on the regulation of respiration and alcoholic fermentation. Yeast 8, 501-517.

Wang, F.Q., Gao, C.J., Yang, C.Y., Xu, P., 2007. Optimization of an ethanol production medium in very high gravity fermentation. Biotechnol. Lett. 29, 233-236.

Xue, C., Zhao, X.Q., Yuan, W.J., Bai, F.W., 2008. Improving ethanol tolerance of a selfflocculating yeast by optimization of medium composition. World J. Microbiol. Biotechnol. 24, 2257-2261.

Yu, J.L., Zhang, X., Tan, T.W., 2009. Optimization of media conditions for the production of ethanol from sweet sorghum juice by immobilized Saccharomyces cerevisiae. Biomass Bioenergy 33, 521-526.

Zhao, X.Q., Xue, C., Ge, X.M., Yuan, W.J., Wang, J.Y., Bai, F.W., 2009. Impact of zinc supplementation on the improvement of ethanol tolerance and yield of selfflocculating yeast in continuous ethanol fermentation. J. Biotechnol. 139, 55-60. 